\title{
Derin ven trombozu ve pulmoner emboli tedavisinde temel prensipler
}

\author{
Basic treatment principles of deep vein thrombosis and pulmonary embolism
}

\author{
Uğur Bengisun
}

Ankara Üniversitesi Tıp Fakültesi, Periferik Damar Cerrahisi Bilim Dalı, Ankara

\begin{abstract}
Venöz tromboemboli (VTE), özellikle travma ve ameliyat sonrası dönemde en ciddi ve en çok korkulan komplikasyonlardan biridir. Derin ven trombozu ve pulmoner emboliden oluşan VTE, hastanede yatan hastalarda ve hastane dışında morbidite ve mortalitenin en önemli nedenlerinden biridir. Bu derlemenin amacı, VTE konusunda halen mevcut tedavi yöntemlerini gözden geçirmektir; özellikle antikoagülan ve trombolitik tedavi, trombektomi ve filtre konuları irdelenecektir.
\end{abstract}

Anahtar sözcükler: tromboemboli; derin ven trombozu; pulmoner emboli; tedavi

\begin{abstract}
Venous thromboembolism (VTE), is one of the most serious and feared complications especially in posttraumatic and postoperative periods. VTE, a disease entity comprising deep vein thrombosis (DVT) and pulmonary embolism $(\mathrm{PE})$, is among the most common causes of morbidity and mortality of patients both hospitalized and out of hospital. The aim of this review is to give an overview of the currently available treatment modalities of VTE. Exclusively, specific aspects regarding the VTE treatment with anticoagulation, thrombolysis, thrombectomy and filters will be discussed.

Key words: thromboembolism; deep venous thrombosis; pulmonary embolism; management
\end{abstract}

d romboembolizm, günümüzde pek çok ülkede morbidite ve mortalitenin majör nedenlerindendir. Venöz tromboemboli (VTE), derin ven trombozu (DVT) ve pulmoner emboliyi (PE) kapsayan genel bir terimdir. VTE, genellikle bacak toplardamarında pıhtı gelişmesi (yani DVT) ve bu pıhtıdan kopan parçanın akciğer damar yatağına göçünden (yani PE'den) ibaret, dünyada ve ülkemizde sık görülen ve önlenebilir, ancak önlenemezse ölüm ile sonuçlanabilen ciddi bir sağlık sorunudur. Hem hastaya ciddi sekeller hem de sağlık sisteminin üzerine belirgin bir ekonomik yük bindiren VTE, hastane ve hastane dışı ölümlerin önemli bir kısmının da nedenidir. Bu yüzden trombotik yani pıhtı ile ilgili olaylardan korunma ve tedavi, tıbbın en önemli alanlarından biri olarak karşımıza çıkmaktadır.

VTE, cerrahi kliniklerinde ve travma olgularında, özellikle ameliyat sonrası dönemde en çok korkulan ve ciddi komplikasyonların başında gelir; son çeyrek asırda VTE nedeni ile açılan malpraktis davaları da konunun önemini bir kat daha arttırmaktadır. ${ }^{[1-4]}$ $\mathrm{Bu}$ derlemenin amacı, DVT ve PE tedavisindeki temel prensipleri irdelemek ve okuyucuyu son literatür ve kılavuzlar ışığında bilgilendirmektir.

VTE tanısı konur konmaz, bu ölümcül patolojinin tedavisine zaman geçirmeden başlanmalıdır. Klinik olarak VTE için şüphe yüksekse ve venöz Doppler ultrasonografi (US), pulmoner bilgisayarlı tomografi (BT) anjiyografi gibi objektif tanı yöntemleri de gecikecekse tedaviye hemen başlanmalıdır. VTE tedavisinin teorik amacı kısa vadede PE ile beraber olan morbidite ve mortaliteyi, uzun vadede ise post-trombotik sendrom ile kronik pulmoner hipertansiyonu engellemektir. Tedavi rejimleri; antikoagülanlar (heparin, warfarin, yeni oral antikoagülanlar [YOAK]), sistemik ya da perkütan trombolitik tedavi yöntemleri, "vena kava"ya filtre uygulamaları yanı sıra günümüzde göreceli olarak daha az başvurduğumuz operatif trombektomilerdir. ${ }^{[1,5-7]}$ DVT tedavi şeması Şekil 1'de sunulmuştur.

- Illetişim adresi: Prof. Dr. Uğur Bengisun, İbni Sina Hastanesi, Akademik Yerleşke K4, Altındağ 06100, Ankara

Tel: 0555 - 3446188 e-posta: ugurbengisun@yahoo.com

- Geliş tarihi: 22 Şubat 2019 Kabul tarihi: 6 Ağustos 2019 


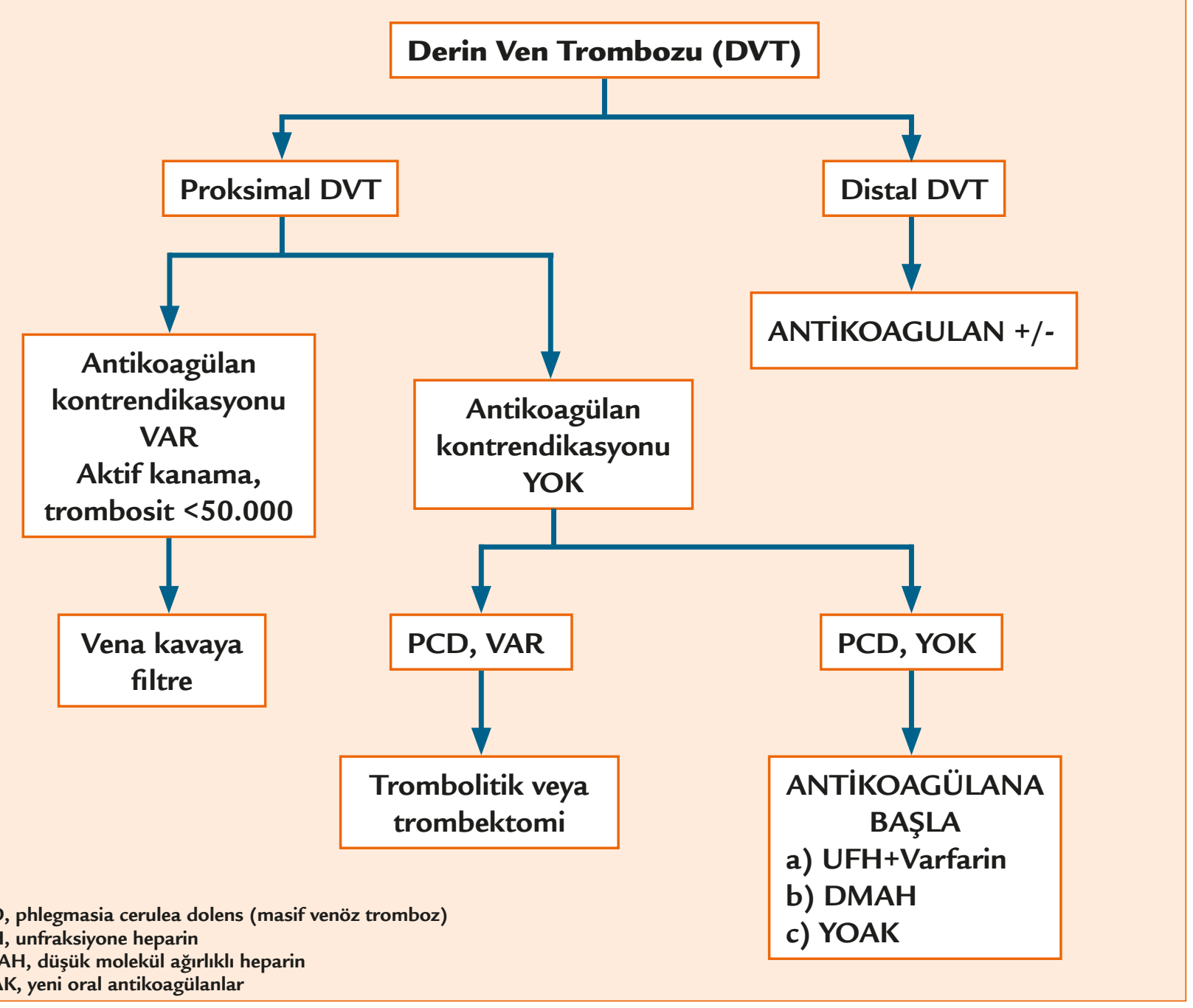

PCD, phlegmasia cerulea dolens (masif venöz tromboz)

UFH, unfraksiyone heparin

DMAH, düşük molekül ağırlıklı heparin

Şekil 1. DVT tedavi şeması.

\section{ANTIKOAGÜLAN TEDAVI}

Antikoagülan tedavi, VTE'nin erken ve geç komplikasyonlarını önleme açısından tedavisinin adeta omurgasıdır. Alt ekstremitenin proksimal venlerinde (popliteal, femoral, iliak venler ve vena kava inferior [VCI]) yerleşen venöz trombozlarda pıhtının büyümesini engellemek ve PE'yi önlemek için antikoagülan tedavi mutlak endikedir. Pek çok klinisyen, diz altındaki bacak venlerinde yerleşen semptomatik distal venöz trombozlarda kanama riski yoksa, antikoagülan tedavi uygulamaktadır.

PE olgularında antikoagülan tedaviye erken dönemde başlanması, nüksü ve mortaliteyi azaltır. Ancak, tüm VTE hastaları, antikoagülan tedavinin en önemli kontrendikasyonu olan kanama açısından titizlikle irdelenmelidir. Kanama riski düşük $(<\% 2)$ hastalarda antikoagülan tedavisine başlanmalı, kanama riski yüksek (>\%13) ya da kontrendike ise antikoagülan uygulanmamalıdır (Tablo 1). ${ }^{[5-8]}$

VTE tedavisinde kullanılan antikoagülan ilaçlar, unfraksiyone heparin (UFH), düşük molekül ağırlıklı heparin (DMAH), K-vit antagonistleri (warfarin), fondaparinuks ve YOAK şeklinde sıralanır.

\section{Heparin}

Geçmişte VTE tedavisi, UFH'nin PE hastalarında mortaliteyi düşürmede başarılı olduğunun tespiti ardından, geleneksel olarak intravenöz uygulama ile 
Tablo 1. Antikoagülan tedavinin kontrendike olduğu durumlar

Aktif, klinik olarak belirgin kanamalar

Ciddi kanama eğilimi

Ciddi trombositopeni

(trombosit sayısı $<50.000 / \mathrm{mikroL}$ )

Majör travma

İnvaziv girişimler veya obstetrik olaylar

(yakın zamanda, acil ya da planlı)

Geçirilmiş intrakraniyal kanama

İntrakraniyal ya da spinal tümör

Nöroaksiyel anestezi

Ciddi kontrolsüz hipertansiyon

başlamıştır. UFH, antitrombine antikoagülan olarak bağlanır ve antitrombinin trombin ve Faktör $X(X a)$ inhibisyonunu arttırır. Yarı ömrü yaklaşık $90 \mathrm{dk}$ olan UFH, bolus intravenöz enjeksiyonu takiben, sürekli infüzyon şeklinde verilir. UFH başlangıç yükleme dozu $80 \mathrm{IU} / \mathrm{kg}$ bolus yapilır ve idame dozu $18 \mathrm{IU} / \mathrm{kg} / \mathrm{sa}$ veya $1300 \mathrm{IU} / \mathrm{sa}$ hızda bir infüzyon pompası ile sürekli infüzyon yapılır. Antikoagülasyonun yeterliliği, aktive parsiyel tromboplastin zamanı (aPTT) ile takip edilir ve her altı saatte bir ölçülür. VTE tedavisi için, aPTT seviyesi kontrol seviyesinin 1,5 kat üzerinde olacak şekilde hedeflenir. Warfarin ile oral antikoagülasyona UFH infüzyonundan bir gün sonra başlanır. Daha sonra, UFH ve warfarin yaklaşık 4-5 gün beraber verilir ve warfarin günlük dozu International Normalized Ratio (INR) 2-3 arasında olacak şekilde ayarlanır. Warfarinin yarılanma ömrünün uzunluğu nedeniyle; UFH, INR 2-3 arasında olduktan iki gün sonra kesilir.

UFH tedavisinin en önemli komplikasyonu kanamadır. Majör kanama (fatal, intrakraniyal, retroperitoneal veya 2 Ü'den fazla eritrosit süspansiyonu gerektiren kanamaların olması) UFH tedavisi gören hospitalize edilmiş hastalarda \%0-2'dir. Bu durumda, antikoagülasyonun kesilmesi ve protamin sülfat ile tamponlama yapılması gerekir.

Heparin ile kompleks oluşturan platelet Faktör IV'e karşı antikorlar oluşması dolayısıyla, heparin ile indüklenen trombositopeni (HIT) görülür. Bu, heparin ile tedavi edilen hastaların \%1-5'inde uygulamanın 5.-15. günlerinde görülmektedir. HIT'in ciddi venöz veya arteriyel trombozlara neden olabilmesi nedeni ile, heparin tedavisi süresince her üç günde bir trombosit sayımı yapılmalıdır. ${ }^{[1,5,6]}$

\section{K-vit Antagonistleri}

Warfarin, şu anda elimizde mevcut olan en eski ve en yaygın şekilde kullanılan oral antikoagülandır. Warfarin etkisini, K-vit bağımlı prokoagülanların (II, VII, IX, X) karaciğerde sentezini inhibe ederek gösterir. Warfarinin tam etkisini göstermesi için birkaç güne ihtiyaç vardır. Bu nedenle, UFH ya da DMAH şeklinde başlanan heparin, warfarin ile terapötik INR elde edildikten sonra kesilmelidir. Warfarine antikoagülasyon yanıtı değişkendir ve bu yanıt, karaciğer fonksiyonu, diyet, yaş ve beraber kullanılan ilaçlara bağlıdır. Warfarin iki gün gibi uzun bir yarı ömre sahiptir ve bu nedenle, kanama riski olabilecek, invaziv girişim yapılacak hastalarda yeterince önceden kesilmelidir. Antikoagülasyon seviyesi INR ile sürekli takip edilmelidir. VTE tedavisinde INR seviyesinin 2-3 arasında tutulması önerilir.

Warfarinin majör komplikasyonu kanamadır. Kanama riski, INR değerinin uzunluğuna bağlıdır. Kanama komplikasyonları, K-vit bağımlı faktörlerin eksikliğinin tamamlanması amacıyla, taze donmuş plazma veya intravenöz K-vit verilerek tedavi edilebilir.

Warfarinden dolayı gelişen diğer bir komplikasyon da deri nekrozudur. Bu komplikasyon, genelde tedavinin ilk günlerinde oluşur, protein $C$ veya $S$ eksikliğine ve maligniteye bağlıdır. Protein $C$ veya $S$ eksikliği olan hastalara warfarin verildiğinde, protein $C$ ve $S$ aniden düşer ve venüllerde tromboz oluşumuna yol açar; bu da, yaygın deri ve subkutan yağ nekrozuna neden olur.

Plasental bariyeri geçmesi ve abortuslar ile doğum defektlerine yol açması nedeni ile, warfarinin gebe kadınlarda kullanılması önerilmez. Heparin ile tedavi edilen VTE'li gebe hastalar, osteopeni açısından takip edilmelidirler.

Heparin ile antikoagülasyonu takiben, warfarin tedavisinin VTE rekürrensini azalttığı gösterilmiştir. VTE için oral antikoagülasyon süresi bireye göre ayarlanmalıdır ve hastanın VTE risk faktörlerine dayalıdır. Geçici immobilizasyon veya östrojen kullanımı gibi tanımlanmış reversibl risk faktörü olan başlangıçtaki VTE'li hastalarda en az üç ay kullanmalıdır. Tanımlanabilir risk faktörleri olmayan ilk kez VTE atağı geçiren hastalarda en az altı ay sürdürülebilir. Tanımlanabilir riski olmayan hastalar rekürrens açısından daha yüksek risk taşıyor olabilirler. Tekrarlayıcı VTE'li olan veya kanser ya da hiperkoagülabilitesi olan hastalar 12 ay veya daha uzun süre tedavi edilmelidirler. ${ }^{[1,5,6]}$

\section{Düşük Molekül Ağırlıklı Heparin (DMAH)}

DMAH'lerin ortalama molekül ağırlıkları $5000 \mathrm{Da}$ olup depolimerizasyon tekniği ile UFH'den geliştirilmiştir. DMAH, Faktör Xa'nın nötralizasyonu için gerekli olan spesifik pentasakkarit dizilimi sayesinde, 


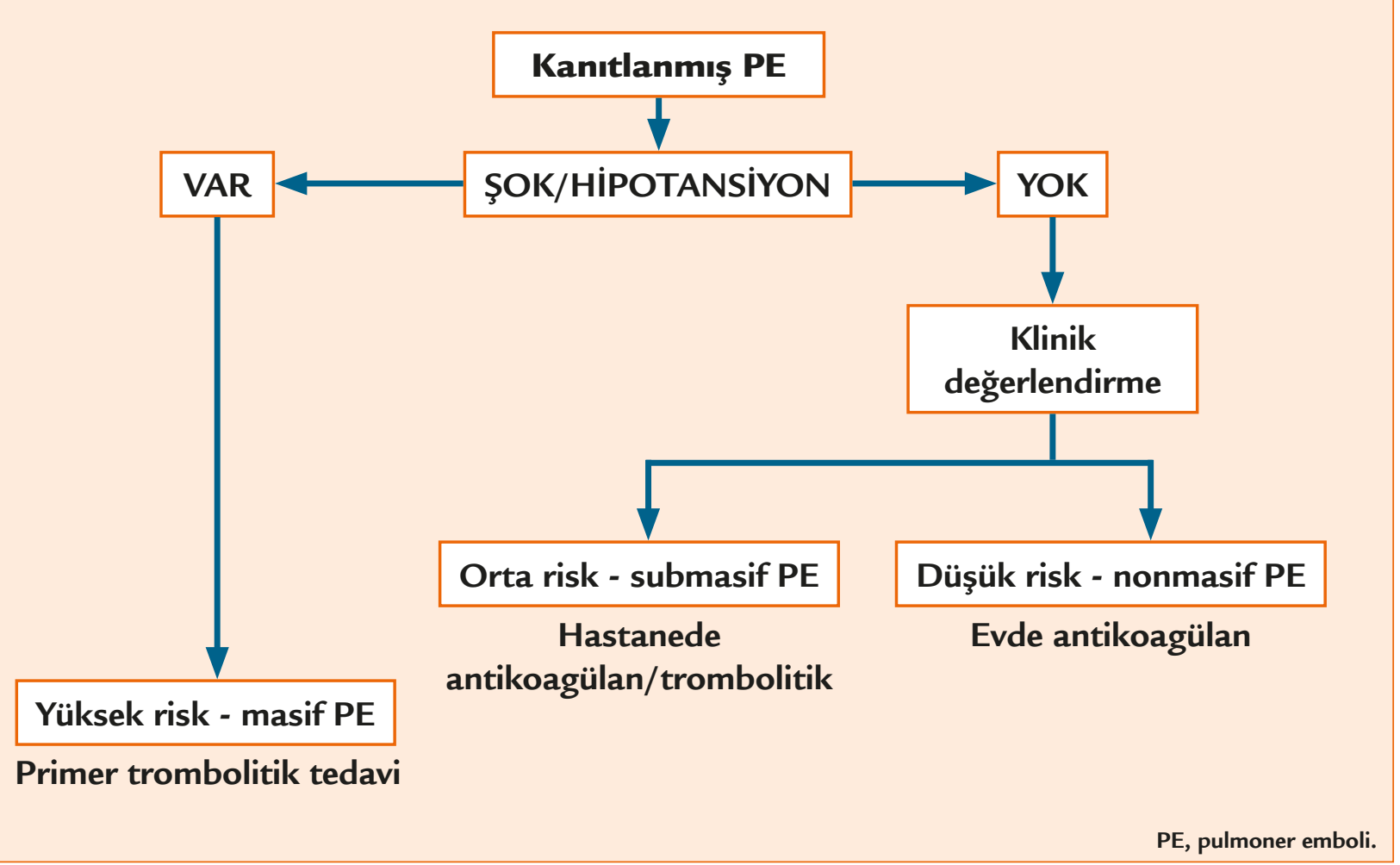

Şekil 2. PE tedavi şeması.

UFH gibi antitrombine bağlanır. DMAH, subkutan enjeksiyon sonrası \%90'nın üzerinde artmış biyo-yararlanıma sahiptir. UFH ile karşılaştırıldığında DMAH, daha uzun yarı ömre sahip olup, plazma proteinlerine ve endotele de daha az bağlanır.

DMAH'nin antikoagülan yanıtı, ağırlığa dayalı dozda verildiğinde etkin ve tahmin edilir olup, bu nedenle rutin laboratuvar izlemi gerekmez. DMAH böbreklerle elimine edilir ve kreatin klirensi $30 \mathrm{~mL} / \mathrm{dk}$ altında olanlarda dikkatli kullanılmalıdır. Gerektiğinde DMAH izlemi, anti-Xa seviyeleri tespit edilerek yapılır. DMAH yüksek seviyelerde gerektiğinde; $50 \mathrm{~kg}$ altında olan çocuklarda, $100 \mathrm{~kg}$ üstünde olan hastalarda, gebelerde ve renal yetmezliği olan hastalarda monitörize edilmelidir. DMAH kısmen protamin sülfat ile tamponlanır. ${ }^{[1,5,6,9,10]}$

\section{Hastane Dışında VTE Tedavisi}

VTE hastalarının hastane dışında ayaktan tedavisi, DMAH'lerin keşfi sayesinde olanaklı hale gelmiştir. DVT'nin ayaktan tedavisini irdeleyen çalışmalar, yöntemin güvenli ve etkin olması dışında hem maliyeti azalttığı hem de yaşam kalitesini arttırdığını ispat etmiştir. Hasta hemodinamik olarak stabil, PE şüphesi düşük ve hastanın kanama riski az olmalıdır. Hastane dışı tedavide, hastanın VTE açısından risk faktörü oluşturan herhangi bir nedenden ötürü hospitalizasyon gereksinimi taşımaması gerekir. Hastanede takibi gereken, ek patolojileri bulunan, masif DVT ve semptomatik PE hastaları ise mutlak hospitalize edilmelidirler (Şekil 2). ${ }^{[1,5,6,11,12]}$

\section{Pentasakkarit}

Fondaparinuks, antitrombine bağlanıp ve spesifik olarak Faktör Xa'yı inhibe eden bir pentasakkarittir; trombini inaktive etmez; trombositler üzerinde etkisi yoktur ve bu nedenle HIT riskini minimalize eder. Hem DVT hem de PE tedavisinde etkinliği gösterilmiştir. Ülkemizde ortopedik cerrahi sonrası profilaksi için ve HIT olgularında rapor ile kullanımı ve geri ödemesi mevcuttur. ${ }^{[5]}$

\section{Yeni Oral Antikoagülanlar (YOAK)}

Ülkemizde de ruhsatı bulunan yeni oral YOAK'lardan rivaroksaban, apiksaban ve edoksaban direkt Faktör $\mathrm{Xa}$ üzerinden, dabigatran ise trombin üzerine direkt 
selektif inhibitör etki gösterir. Hızlı etki göstermeleri, oral yolla kolay kullanımları, warfarinin aksine laboratuvar kontrolü gerektirmemeleri, yiyecek etkileşimlerinin bulunmaması, ilaç etkileşimlerinin nadir olması gibi pek çok avantaja sahip olan YOAK'lar, spesifik antidotlarının halen gelişme aşamasında olması, ileri yaş, renal yetmezlik, gebelik, kanser ve benzeri bazı özel medikal durumlarda tedavi yönetiminin kesin olmaması gibi dezavantajlara sahiptir.

\section{Rivaroksaban (Xarelto ${ }^{\circledR}$ )}

Faktör Xa direkt inhibisyonu yapan rivaroksaban ile DVT ve masif olmayan PE tedavisinde, $2 \times 15 \mathrm{mg} /$ gün dozunda başlanıp üç hafta sonunda $20 \mathrm{mg}$ /gün dozunda devam edilir.

\section{Dabigatran eteksilat (Pradaxa ${ }^{\circledR}$ )}

Direkt trombin inhibitörüdür. DMAH tedavisini takiben sekonder profilaksi ve masif olmayan PE'nin idame tedavisinde kullanılır.

\section{Apiksaban (Eliquis ${ }^{\circledR}$ )}

Faktör Xa direkt inhibitörüdür. Masif olmayan PE tedavisinde kullanılabilir.

\section{Edoxaban (Lixiana ${ }^{\circledR}$ )}

Faktör Xa direkt inhibitörüdür. Akut VTE'li hastalarda beş günlük heparin tedavisini takiben kullanılabilir. ${ }^{[1,5,13-17]}$

\section{Antikoagülan Tedavi Süresi}

Nüks ve erken mortaliteyi önlemek için cerrahi ya da diğer geçici risk faktörlerine bağlı VTE hastalarında antikoagülan tedavi en az üç ay sürdürülmelidir. İdiyopatik VTE'lerde en az 3-6 ve bu grup hastalarda ikinci tromboz atağı durumunda ise daha da uzatılmış antikoagülan tedavi yapılmalıdır. Kanser hastalarında en az 3-6 ay olmakla birlikte, aktif kanser varlığında antikoagülan tedavi daha uzun süre verilir. DMAH, aktif kanser ve VTE bulunan hastalarda warfarine göre daha etkili ve güvenli bulunduklarından tercih edilir. ${ }^{[1,5,13]}$

\section{Phlegmasia Cerulea Dolens (PCD)}

Masif venöz tromboz olarak da bilinen PCD'nin, nadir görülmesine karşın trombolitik ve/veya trombektomi gibi agresif tedaviler gerekebildiği için, sıradan DVT'lerden ayrımı önemlidir. Plegmasia alba dolens'ten venöz gangrene kadar farklı kliniklere yol açabilen PCD, genellikle 5.-6. dekadlarda ve kadın cinsiyette görülür. En önemli tetikleyici faktör malignitedir. Ekstremitede ani ortaya çıkan ciddi şişlik, ağrı, siyanoz

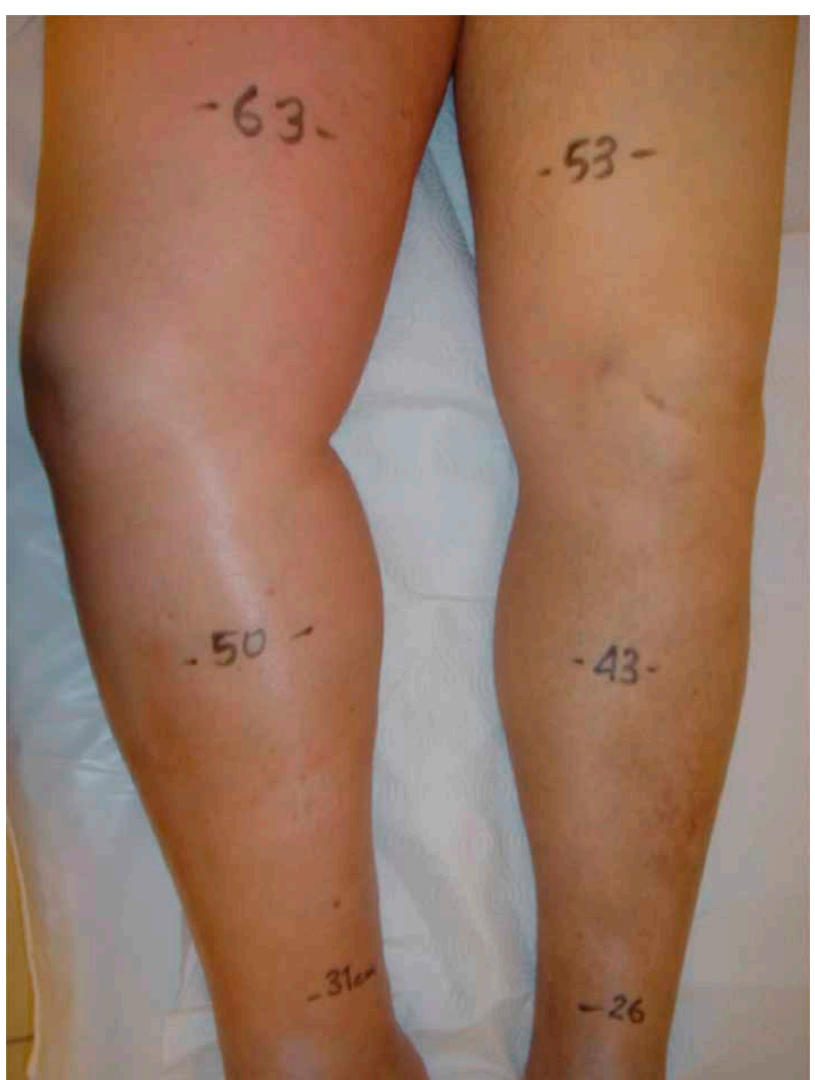

Şekil 3. Sağ alt ekstremitede PCD olgusu.

ve kompartman sendromu ile seyreden bir klinik tablo oluşturur. Ekstremite venöz drenajının ciddi şekilde bozulması, masif sıvı sekestrasyonuna, bül, siyanoz ve arteriyel yetmezlik sonucu gangrene, dolayısı ile ekstremite kaybına yol açabilir (Şekil 3). ${ }^{[5,6,18-20]}$

\section{Trombolizis}

Akut alt ekstremite DVT'li hastaların çoğunda, tek başına antikoagülan tedavi yeterlidir. PCD'li veya masif iliofemoral venöz trombozlu hastalar ile antikoagülan tedavinin başarısız olduğu hastalarda trombolitik ve/ veya trombektomi endikedir. Pıhtının henüz organize olmadığı, semptomların başlamasından 14 günden fazla geçmemiş, akut DVT'li, iyi fonksiyonel durumda, kanama riski düşük hastalar, en uygun adaylardır. Hızlı şekilde tamamen pıhtı yükünden kurtulma, kapak fonksiyonlarını koruma dolayısı ile, posttrombotik sendrom görülme sıklığı azalır. Geçmişte sistemik olarak uygulansa da, potansiyel komplikasyonlarından ötürü, günümüzde trombolitik ajan kateter ile sadece pıhtı bulunan damara verilir. Akut iliofemoral DVT'si 
olan hastalarda, kateter aracılı̆̆ı ile yapılan trombolitik tedavinin trombozun ortadan kaldırılmasında etkili olduğu görülmüştür. Venöz girişim, genellikle aynı taraf popliteal ya da tibial venden yapılır. Trombozun yaygınlığı ve seviyesinin tespiti için venogram yapılır. Trombozun içinden kılavuz tel yerleştirilmesini takiben, çok delikli infüzyon kateterine pozisyon verilir. Daha sonra, trombolitik ajan tromboz içine direkt olarak verilir. Gelişen teknoloji sayesinde, hem pıhtıyı parçalayan hem de eriten yöntemler de farmakomekanik trombektomi adı ile kullanıma girmiştir.

Trombolitik tedavi, özellikle ilk 24 saat içinde uygulanırsa, PE'den gelişen perfüzyon bozukluğunu ve hemodinamik olayları tersine çevirip hayat kurtarıcı olabilir (Şekil 2). Bununla beraber, klinik pratikte az sayıda PE hastası trombolitik tedaviye adaydır $(<\% 10)$ ve kullanımı oldukça bireyseldir. PE tedavisinde trombolitik tedavi, persistan hipotansiyonun geliştiği masif PE'de kullanılır. Yüksek riskli submasif PE'li hastalarda trombolitik tedaviye alternatif olarak perkütan kateter ile lokal trombolitik tedavi yöntemleri de kullanıma girmiştir. Sistemik trombolitik tedavinin majör komplikasyonu kanamadır. Trombolitik tedavi; aktif internal kanaması olanlarda, yakın zamanda serebrovasküler olay geçirenlerde $(<2$ ay) ve intrakraniyal patolojisi olanlarda kontrendikedir. Relatif majör kontrendikasyonlar ise; majör travma, kontrolsüz hipertansiyon, aktif gastrointestinal patoloji, yakın zamanda majör cerrahi (<10 gün) ve oküler patoloji içerir.

Klinik kullanımda üç trombolitik ajan mevcuttur: streptokinaz, ürokinaz ve rekombinant doku plazminojen aktivatörü (rtPA). Bu üç ajanın hepsi de plazminojeni plazmine aktive eder, fibrin degradasyonu ve trombolize yol açar. Klinikte genellikle plazminojen aktivatörü (tPA) kullanımı revaçtadır.

Tüm insan dokularında tPA mevcuttur ve ilk olarak 1979 yılında izole edilmiştir. Rekombinant formu olan rtPA (Actylse ${ }^{\circledR} 50 \mathrm{mg}$ flakon) piyasada mevcuttur. Fibrine bağlı plazminojen açısından streptokinaz veya ürokinazdan daha özgüldür. Fakat, trombüsün erimesi veya kanama komplikasyonlarını azaltma açısından üstünlügü yoktur. Masif PE tedavisinde rtPA, iki saatte bir $100 \mathrm{mg}$ infüzyon olarak verilir.

PE'nin çıkarılmasında perkütan transvenöz kateter tekniği; mekanik yolla trombüsün parçalanması, aspirasyonu, reolitik, ultrasonik trombektomi gibi teknikleri içerir. Mekanik pıhtı parçalanması, kateter aracılığı ile uygulanan trombolizisi takip eder. Hemodinamik olarak stabil submasif PE hastalarında büyük başarı ile uygulanmaktadır. ${ }^{[1,5,6,13,18-20]}$

VTE konusunda en yetkin oluşum olan American College of Chest Physicians (ACCP), günümüzde trombolitik tedavinin bireye göre ve hemodinamik olarak stabil olmayan masif $\mathrm{PE}$ veya düşük kanama riski olan masif iliofemoral trombozlu hastalarda kullanılmasını önermektedir. ${ }^{[1,5,13]}$

\section{Vena Kava İnferior ( $\mathrm{VCI}$ ) Filtreleri}

İlk filtreler femoral venden cerrahi olarak yerleştirilmiş olsa da, halen günümüzde $\mathrm{VCl}$ filtresi, floroskopi veya ultrasonografi (US) altında femoral ven veya jugüler venden perkütan minimal invaziv tekniklerle infrarenal vena kavaya yerleştirilir. Akut proksimal DVT veya PE'li bir hastada $\mathrm{VCl}$ filtresi yerleştirilmesinde genel olarak kabul gören endikasyonlar, antikoagülasyona kontrendikasyon ya da antikoagülan tedavinin kesilmesi zorunluluğu ortaya çıkması ve PE'si olan veya yüksek riskli PE'si bulunan bir hastada antikoagülasyonun yetmezliğidir. Bu tür hastalara, optimal antikoagülasyona rağmen PE gelişen hastalar da eklenebilir. Filtre yerleştirilmiş hastada kanama riski düştüğünde filtre çıkarılıp antikoagülan tedavi başlanması önerilir. Filtre yerleştirmesine bağlı komplikasyonlar; ponksiyon yerinde venöz tromboz, filtre migrasyonu, $\mathrm{VCl}$ duvarının içine filtre erozyonu ve $\mathrm{VCl}$ obstrüksiyonunu içerir. Fatal komplikasyon oranı \%0,12'den azdır. ${ }^{[1,5,13,21,22]}$

\section{AÇIK CERRAHI TEDAVI}

\section{iliofemoral DVT'de Trombektomi}

Günümüzde, görüntüleme tekniklerindeki ve girişimsel yöntemlerindeki ilerlemeler sayesinde, açık cerrahi ile trombektomiye nadiren başvurmaktayız. Akut iliofemoral DVT'si olan hastalarda açık cerrahi tedavi genellikle, antikoagülasyon ile kötüye giden, trombolitik tedavinin kontrendike olduğu PCD'li ve venöz gangrenli hastalarda tercih edilir. Hastada PCD mevcutsa, ilk olarak bacak kompartmanlarının fasyotomisi yapılır. Illiofemoral DVT'de ana femoral vende (CFV) longitudinal venotomi yapılır, venöz balon embolektomi kateteri tromboz içinden VCl'ya doğru itilir ve tromboz gelmeyinceye kadar ileri geri hareket ettirilir. Bacaktaki distal tromboz, ayaktan başlanan manuel basınç uygulaması ile çıkarılır. Bu, ayaktan başlayıp uyluğa doğru sarılan lastik bandaj ile uygulanır. Femoral vendeki tromboz eski ve çıkarılamıyorsa, ven bağlanır. VCl'ya doğru uzanan tromboz için VCl transperitoneal olarak görülür ve $\mathrm{VCI}$ renal venlerin altında kontrol edilir. $\mathrm{VCI}$ açılır ve tromboz nazik bir masaj ile çıkarılır. Rezidüel tromboz veya stenozun olup olmadığının tespiti için ameliyat sırasında venogram yapılır. Rezidüel iliak ven stenozu mevcutsa, ameliyat sırasında anjiyoplasti ve stentleme uygulanabilir. Pek çok olguda bir arteriyovenöz fistül, trombektomize iliofemoral venöz segmentin açıklığını idame etmek amacıyla safen ven (VSM) ile 
süperfisiyel femoral arter arasında uç-yan (end-to-side) anastomoz yapılır. Heparin, ameliyat sonrası birkaç gün verilir. Warfarin ile antikoagülasyona, trombektomi sonrası en az altı ay devam edilir. ${ }^{[23]}$

Cerrahi pulmoner embolektomide hayatta kalım oranları yaklaşık son 30 yılda kardiyopulmoner bypass eklenmesi ile iyileşmiştir. Akut PE'de acil pulmoner embolektomi nadiren endikedir. Masif pulmoner embolisi olan hastalarda, trombolizis başarısızlığı veya trombolitiklere kontrendikasyon mevcutsa, bu prosedür uygulanabilir. Açık pulmoner arter embolektomisi torakotomi aracılığıla pulmoner arterin direkt görülmesi şeklinde uygulanır. Başlangıçta mortalite oranı \%20-40 arasında iken, son yıllarda \%6'ya kadar düşmüştür. ${ }^{[5,6]}$

\section{Yüzeyel Venöz Tromboz ya da Tromboflebit}

Yüzeyel venöz tromboz (YVT) normal venlerde de gelişmekle birlikte, sıklıkla variköz venlerde oluşur. WT, sıklıkla ven içine yerleştirilen bir kateterden kaynaklanır ve çoğu zaman sefalik vende gelişir. Normal yüzeyel venlerin değişik yerlerinde VVT tekrarlarsa, bu bir visseral malignitenin veya hematolojik ve/veya kollajen vasküler hastalık gibi bir sistemik hastalığın belirtisi olabilir. Bu durum "thrombophlebitis migrans" olarak da bilinmektedir.

WT'nin klinik bulguları; etkilenen ven boyunca kızarıkıı, ısı artışı ve hassasiyeti içerir; genelde palpabl bir kordon tespit edilir. Süpüratif WT'si olan hastalarda ateş ve lökositoz olabilir. Dupleks US (DUS), akut WT semptom ve bulguları olan hastalarda yüzeyel venlerde trombozu göstererek tanıyı doğrulamak aynı zamanda DVT ile beraber olup olmadığının tespiti için uygulanmalıdır. WT'lerin beraberinde DVT olma olasılığı \%540 arasındadır. Proksimal VSM'de VT'si olan hastalarda DVT olsun olmasın 5-7 gün sonra kontrol amaçlı DUS yapılmalıdır. Çünkü, bu hastalarda trombozun derin venöz sisteme yayılma riski mevcuttur. Proksimal VSM'yi ilgilendiren WT hastaların yaklaşık \%10-20'sinde bir hafta içinde derin venöz sisteme ilerleme olur. ${ }^{[8]}$

VVT tedavisi bireyseldir ve trombozun lokalizasyonu ve semptomların ciddiyetine bağlıdır. Safenofemoral bileşkenin $1 \mathrm{~cm}$ içinde olmayan YVT'li hastalarda tedavi, kompresyon ve indometazin gibi anti-inflamatuvar ilaçların verilmesidir. Süpüratif YVT'si olan hastalarda ise, kateter mevcutsa çıkarılması şarttır ve venin eksizyonu gerekli olabilir. YVT safenofemoral bileşkenin 1 $\mathrm{cm}$ proksimaline yayılıyor ise, CFV'ye yayılma büyük olasilıkla mevcuttur. Bu hastalarda ise, altı hafta süreyle antikoagülasyon veya VSM ligasyonu, trombozun derin venöz sisteme yayılmasının engellenmesinde eşit etkiye sahiptir. ${ }^{[24,25]}$

\section{Üst Ekstremite Ven Trombozu (Aksiler-Subklaviyan Ven Trombozu)}

Aksiler-subklaviyan ven trombozu (ASVT) iki formda sınıflanır. Primer ASVT, tüm ASVT hastalarının sadece küçük bir bölümünü içerir. Primer formda ilk incelemede tromboza yol olan açık bir neden bulunmaz. Primer ASVT, üst ekstremiteyi yukarı kaldırıp uzun ve tekrarlayan hareketlerle klavikula ve birinci kosta arasından geçen subklaviyan vene hasar verilmesi sonucu gelişir. Bu durum, venöz torasik outlet sendromu olarak bilinir. Sekonder ASVT daha sıktır ve kateter uygulanması veya hiperkoagülabilite gibi nedenlere dayalıdır. Subklaviyan ven içinde tünelize kateter bulunan hastaların \%30'unda ASVT gelişir.

ASVT'li hasta asemptomatik olabilir veya üst ekstremitede değişen oranlarda şişme ve hassasiyet bulunabilir. Tanıyı doğrulamak için DUS yapılır. ASVT tanısı konulduktan hemen sonra, PE'nin önlenmesi ve semptomların azaltılması için antikoagülasyona başlanmalıdır. Akut semptomatik primer ASVT'li hastalar trombolitik tedavi için aday olabilirler. Trombolitik tedavinin tamamlanmasından sonra, düzeltilebilir anatomik problemin ortaya konması için kontrol venogramı yapılır. Rezidüel venöz daralma için balon anjiyoplasti ve torasik outlet anormallikleri için servikal veya birinci kot rezeksiyonu, trombolitik tedavi sonrası yardımcı girişimleri içerir. ${ }^{[26]}$

ACCP 2016 yılı VTE antitrombotik tedavi önerileri aşağıda özetlenmiştir ${ }^{[27]}$ :

- Akut proksimal DVT ya da PE tedavisinde üç ay antikoagülan tedavi önerilir. Kanserin söz konusu olmadığı VTE hastalarında warfarin yerine öncelikli olarak YOAK'lar üç ay boyunca önerilmektedir. YOAK kullanılamıyorsa, akut proksimal DVT ya da PE tedavisinde 2012 kılavuzunda önerildiği gibi ilk olarak DMAH, fondaparinuks veya $\mathrm{AH}$ ile parenteral tedaviye başlanıp, hastalara aynı gün K-vit antagonisti warfarin verilmesi ve INR $>2$ olana kadar devam edilmesi önerilmektedir.

- Kanser ile ilgili DVT ya da PE gelişmiş hastalar$\mathrm{da}$, ilk üç ay antikoagülan tedavi için warfarin ve YOAK yerine DMAH'ler önerilir. Aktif kanser hastalarında üç aydan uzun tedavi önerilir.

- Cerrahi sonrası tetiklenmiş olan proksimal DVTya da PE olgularında üç ay süreyle antikoagülan tedavi önerilmektedir. Cerrahi dışı geçici bir nedenle tetiklenmiş olan proksimal DVT ya da PE olgularında ise kanama riski yüksek değilse üç ay antikoagülan tedavi önerilir.

- Cerrahi sonrası ya da cerrahi olmayan geçici risk faktörleri tarafından tetiklenmiş izole distal DVT 
olgularında üç ay antikoagülan tedavi önerilir. Asemptomatik, proksimal venlere yayılım için risk bulunmayan hastalarda antikoagülan önerilmez. Bu hastalara derin venlere yönelik inceleme ile takip önerilir.

- Herhangi bir nedenle tetiklenmemiş ilk kez DVT ya da PE geçiren olgularda, kanama riski yüksekse üç ay, kanama riski yüksek değilse üç aydan uzun bir süre antikoagülan tedavi önerilir. Üç ayın sonunda bu hastalar, daha uzun süreli tedavi verip vermeme açısından tekrar değerlendirilmelidir. Antikoagülan tedavinin kesileceği hastalarda VTE'nin tekrarından korunma için, kontrendikasyon yoksa aspirin kullanılması önerilir.

- Akut proksimal DVT'li hastalarda kateter ile trombolitik yerine antikoagülan tedavi önerilmektedir. Ancak, post-trombotik sendrom riski yüksek, kanama riski ve maliyeti düşük hastalar, kateter ile trombolitik tedaviden yarar görebilir.

- Akut DVT veya PE ile gelen ve antikoagülan ile tedavi edilen hastalarda VCI filtresi kullanımı tavsiye edilmemektedir.

- Akut DVT veya masif olmayan düşük riskli PE tanısı alıp evde takibi uygun hastalarda başlangıç tedavisine evde başlanabilir ya da hastanede başlanıp evde devam edilmesi önerilir.

- Akut PE ile gelen bir hastada beraberinde hipotansiyon (sistolik kan basıncı $<90 \mathrm{~mm} \mathrm{Hg}$ ) olması durumunda, kanama riski düşükse sistemik trombolitik tedavi verilmesi önerilir. Beraberinde hipotansiyon olmayan akut PE ile gelen hastaların çoğunda sistemik trombolitik tedavi verilmesi önerilmemektedir.

- PE’nin başlangıç tedavisi için kateter ile pıhtı çıkarma yöntemleri, hipotansiyon ve sistemik trombolitik için yüksek kanama riski olan, sistemik tedavinin başarısız olduğu hastalarda tercih edilmelidir.

- Aksiler ve daha proksimal venlerdeki üst ekstremite DVT hastalarında, öncelikle antikoagülan tedavi önerilir.

\section{SONUÇ}

VTE halen ciddi bir morbidite ve mortalite nedeni olarak karşımızdadır. Özellikle hastanede yatan hastaların VTE risk değerlendirilmesi ile optimal profilaksi yapılması gereklidir. VTE ile gelen hastaların tedavisinde antikoagülanlar halen tedavinin en önemli unsurudur. Yeni oral antikoagülanlar ve kateter temelli pihtı tedavileri maliyet analizi ve risk/yarar oranları gözetilerek kullanılmalıdır.

\section{KAYNAKLAR}

1. Piran S, Schulman S. Management of venous thromboembolism: an update. Thromb J 2016;14(Suppl 1):107-15. Crossref

2. Prandoni P, Lensing AWA, Cogo A, Cuppini S, Villalta S, Carta M, Cattelan AM, Polistena P, Bernardi E, Prins MH. The longterm clinical course of acute deep venous thrombosis. Ann Intern Med 1996;125(1):1-7. Crossref

3. LaMori JC, Shohieber O, Mody SH, Bookhart BK. Inpatient resource use and cost burden of deep vein thrombosis and pulmonary embolism in the United States. Clin Ther 2015;37(1):62-70. Crossref

4. Can iÖ, Özkara E, Can M. Yargıtayda karara bağlanan tıbbi uygulama hatası dosyalarının değerlendirilmesi. DEÜ Tıp Fak Derg 2011;25(2):69-76.

5. Arseven O, Okumuş NG, Öngen G, Müsellim B, editörler. Türk Toraks Derneği Pulmoner Tromboembolizm Tanı ve Tedavi Uzlaşı Raporu Cep Kitabı. İstanbul: Aves Yayıncılık; 2015. https://www.toraks.org.tr/uploadFiles/book/ file/112201615430-Tamami.pdf

6. Güven Platformu. Ulusal Venöz Tromboembolizm Profilaksi ve Tedavi Kılavuzu -2010. İstanbul: Cortex Illetişim Hizmetleri A. Ş. Diasan Basım Form Matbaacılık; 2010.

7. Smith SB, Geske JB, Maguire JM, Zane NA, Carter RE, Morgenthaler TI. Early anticoagulation is associated with reduced mortality for acute pulmonary embolism. Chest 2010;137(6):1382-90. Crossref

8. Schwarz T, Buschmann L, Beyer J, Halbritter K, Rastan A, Schellong S. Therapy of isolated calf muscle vein thrombosis: a randomized, controlled study. J Vasc Surg 2010;52(5):124650. Crossref

9. Lee AY, Kamphuisen PW, Meyer G, Bauersachs R, Janas MS, Jarner MF, Khorana AA; CATCH Investigators. Tinzaparin vs warfarin for treatment of acute venous thromboembolism in patients with active cancer: A randomized clinical trial. JAMA 2015;314(7):677-86. Crossref

10. Lyman $\mathrm{GH}$, Khorana AA, Kuderer NM, Lee AY, Arcelus JI, Balaban EP, Clarke JM, Flowers CR, Francis CW, Gates LE, Kakkar AK, Key NS, Levine MN, Liebman HA, Tempero MA, Wong SL, Prestrud AA, Falanga A; American Society of Clinical Oncology Clinical Practice.. American Society of Clinical Oncology Clinical Practice. Venous thromboembolism prophylaxis and treatment in patients with cancer: American Society of Clinical Oncology clinical practice guideline update. J Clin Oncol 2013;31(17):2189204. Crossref

11. Zondag W, Kooiman J, Klok FA, Dekkers OM, Huisman MV. Outpatient versus inpatient treatment in patients with pulmonary embolism: a meta-analysis. Eur Respir J 2013;42(1):134-44. Crossref

12. Levine M, Gent M, Hirsh J, Leclerc J, Anderson D, Weitz J, Ginsberg J, Turpie AG, Demers C, Kovacs M.. Comparison of low-molecular-weight heparin administered primarily at home with unfractionated heparin administered in the hospital for proximal deep-vein thrombosis. N Engl J Med 1996;334(11):677-81. Crossref

13. Guyatt GH, Akl EA, Crowther M, Gutterman DD, Schuünemann HJ; American College of Chest Physicians Antithrombotic Therapy and Prevention of Thrombosis Panel. Antithrombotic Therapy and Prevention of Thrombosis, 9th ed. American College of Chest Physicians Evidence-based Clinical Practical Guidelines. Chest 2012;141(2 Suppl):7S47S. Crossref 
14. The EINSTEIN Investigators, Bauersachs R, Berkowitz SD, Brenner B, Buller HR, Decousus H, Gallus AS, Lensing AW, Misselwitz F, Prins MH, Raskob GE, Segers A, Verhamme $P$, Wells $P$, Agnelli G, Bounameaux $\mathrm{H}$, Cohen A, Davidson BL, Piovella F, Schellong S. Oral rivaroxaban for symptomatic venous thromboembolism. N EngIJ Med 2010;363(26):2499510. Crossref

15. Schulman S, Kearon C, Kakkar AK, Mismetti P, Schellong $\mathrm{S}$, Eriksson H, Baanstra D, Schnee J, Goldhaber SZ. Dabigatran versus Warfarin in the Treatment of Acute Venous Thromboembolism. N Engl J Med 2009;361(24):2342-52. Crossref

16. Agnelli G, Buller HR, Cohen A, Curto M, Gallus AS, Johnson M, Masiukiewicz U, Pak R, Thompson J, Raskob GE, Weitz JI; AMPLIFY Investigators.. Oral apixaban for the treatment of acute venous thromboembolism. N Engl J Med 2013;369(9):799-808. Crossref

17. Hokusai-VTE Investigators. Büller HR, Décousus H, Grosso MA, Mercuri M, Middeldorp S, Prins MH, Raskob GE, Schellong SM, Schwocho L, Segers A, Shi M, Verhamme P, Wells P.. Edoxaban versus warfarin for the treatment of symptomatic venous thromboembolism. N Engl J Med 2013;369(15):1406-15. Crossref

18. Bashir R, Zack CJ, Zhao H, Comerota AJ, Bove AA. Comparative outcomes of catheter-directed thrombolysis plus anticoagulation vs anticoagulation alone to treat lowerextremity proximal deep vein thrombosis. JAMA Intern Med 2014;174(9):1494-501. Crossref

19. Oguzkurt L, Tercan F, Ozkan U. Manual aspiration thrombectomy with stent placement: rapid and effective treatment for phlegmasia cerulea dolens with impending venous gangrene. Cardiovasc Intervent Radiol 2008;31(1):205-8. Crossref
20. Laiho MK, Oinonen A, Sugano N, Harjola VP, Lehtola AL, Roth WD, Keto PE, Lepäntalo M.. Preservation of venous valve function after catheter-directed and systemic thrombolysis for deep venous thrombosis. Eur J Vasc Endovasc Surg 2004;28(4):391-6. Crossref

21. PREPIC Study Group. Eight-year follow-up of patients with permanent vena cava filters in the prevention of pulmonary embolism: the PREPIC (Prevention du Risque d'Embolie Pulmonaire par Interruption Cave) randomized study. Circulation 2005;112(3):416-22. Crossref

22. Wu A, Helo N, Moon E, Tam M, Kapoor B, Wang W. Strategies for prevention of iatrogenic inferior vena cava filter entrapment and dislodgement during central venous catheter placement. J Vasc Surg 2014;59(1):255-9. Crossref

23. Aksoy M, Dilege S. iliofemoral derin ven trombozlu olguların tedavisinde trombektomi. T Klin Cerrahi 2003;8:108-12.

24. Anadol E, Bengisun U. Septik tromboflebit. İçinde: Topçu AW, Söyletir G, Doğanay M, editörler. İnfeksiyon Hastalıkları ve Mikrobiyolojisi Kitabı. Nobel Tip Kitabevi 2002. ss.731-3.

25. Blaettler W, Schwarzenbach B, Largiader J. Superficial vein thrombophlebitis -serious concern or much ado about little? VASA 2008;37(1):31-8.

26. Vemuri $C$, Salehi $P$, Bennaroch-Gampel J, McLaughlin LN, Thompson RW. Diagnosis and treatment of effort-induced thrombosis of the axillary subclavian vein due to venous thoracic outlet syndrome. J Vasc Surg Venous Lymphat Disord 2016;4(4):485-500. Crossref

27. Kearon C, Akl EA, Ornelas J, Blaivas A, Jimenez D, Bounameaux $H$, Huisman M, King CS, Morris TA, Sood N, Stevens SM, Vintch JRE, Wells P, Woller SC, Moores L. Antithrombotic Therapy for VTE Disease: CHEST Guideline and Expert Panel Report. Chest 2016;149(2):315-52. Crossref 